\title{
A divergência do campo do fluxo de vapor d'água e as chuvas na regiào Amazônica
}

\author{
José Marques (') \\ Eneas Salati ${ }^{(2)}$ \\ Jesus Marden dos Santos [ ${ }^{3]}$
}

\section{Resumo}

Foram estimados, a partir dos dados de radiossondagens do periodo $1972 / 1975$, os valores da divergência do campo do fluxo de vapor d'água sobre a bacia Amazônica, $\overrightarrow{\nabla . Q}$. De um modo genérico, hcuve predominância dos valores negativos da divergência, ficando evidenciadia sua relação com o campo da precipitação, principalmente no mês de março. Utilizando os valores de $\nabla \overrightarrow{. Q}$ estimou-se em $172.616 \mathrm{~m}^{3} / \mathrm{s}$ o valor médio da vazăo do río Amazonas no período estudado, constituindo-se em um método independente para estimativas de vazão em grandes bacias, mesmo desconhecendo-se os valores da precipitação e da evapotranspiração. Comparaçōes com outros resultados utilizandose metodologias distintas foram feitas, tendo o método aerológico mcstrado ser útil inclusive para a previsão de vazões mensais com antecedência de 3 meses na bacia Amazônica. Foi de $2328 \mathrm{~mm} /$ ano a precipitação média no período estudado na bacia.

\section{INTRODUÇÃo}

Os estudos da circulação geral da atmosfera conduziram a uma nova metodologia de pesquisas hidrológicas baseadas na análise dos campos das diversas grandezas que caracterizam o estado da atmosfera e a dinâmica da água na fase vapor. Utilizando esta metodologia Marques et al. (1979a, 1979b) caracterizaram os campos do transporte e do armazenamento aéreo do vapor d'água atmosférico sobre a bacia Amazônica. No presente trabalho, terceiro da série, estuda-se a divergência do campo do transporte aéreo do vapor d'água, demonstrando-se que ele está bem associado com o campo de precipitação. constituindo também um método independente para estimativas da vazão em grandes bacias, mesmo desconhecendo-se os valores da precipitação e da evapotranspiraçăo.

\section{REVISÃO DA LITERATURA}

Pesquisas recentes têm permitido obter informações do balanço hídrico de uma vasta região a partir do estudo dos campos de dis. tribuição dos parâmetros que caracterizam o comportamento do vapor dágua na atmostera, podendo-se inferir o balanço hídrico de uma região a partir do estudo do "ramo aéreo" do ciclo hidrológico, Peixoto $(1968,1970)$.

Vários estudos utilizando esta metcdolo gia foram feitos, podendo serem citados os trabalhos de Benton \& Estoque (1954) e Rasmusson $(1966,1967)$ para os Estados Unidos; para o mar Báltico por Palmén \& Sóderman (1966); para a Austrália por Hutchings (1961) e para a bacia Amazônica por Molion (1975) e Marques (1976) e Marques et al. (1977). Cobrindo todo o hemisfério norte, citamos o trabalho de Peixoto (1970): Peixots et al (1976) apresentaram um estudo cobrindo todo o globo.

Benton et al. (1950) utilizaram o método para o balanço hidrológico na bacia do rio Mississipi e concluiram que, a maior parte da chuva caída na região provinha de vapor dágua oriundo do oceano e transportado peios ventos. Segundo os autores não foi necessária a existência de uma alta correlaçāo entre os valores mensais da transferência de vapor d'água e da precipitação, mas esta foi mais associada aos valores negativos da divergência (convergência) do campo de vapor d'água atmosférico do que com sua transferência. Bettencourt et al. (1970) afirmaram que pe quenos valores de fluxo de vapor não estão associados a valores elevados da precipitação mas a existência de alto valor do fluxo de

(1) - UFRJ - I. Geociências, Departamento de Meteorologia

(2) - Instituto Nacional de Pesquisas da Amazônia, Manaus

(3) - CENA - Centro de Energia Nuclear na Agricultura 
vapor é condição necessária mas não suficiente para a ocorrência de chuvas em uma região.

Hutchings (1957), na Inglaterra, comparando os dados medidos de chuva e evapotranspiração com os estimados a partir da divergência do campo do fluxo de vapor, no verão, concluiu ser a divergência um bom índice de estimativa, podendo ser utilizado para fornecer uma visão correta do balanço de água também em áreas relativamente pequenas.

\section{MATERIAL E MÉtodos}

Os dados de precipitação (P) utilızados no presente estudo foram obtidos a partir do levantamento dos totais mensais de 117 estações na região e adjacências cobrindo o perío. do 1972/1975 com os quais foram traçadas cartas mensais e anuais do campo da precipitação. Os dados básicos de altitude foram os mesmos utilizados em Marques et al. (1979a). A partir destes dados foram computados os campos do fluxo de vapor d'água atmosférico $(\vec{Q})$ Marques et al. (1979a) bem como a sua divergência $(\nabla \cdot \vec{Q})$ na região e o armazenamento atmosférico, representadio pela água precipitável, Marques et al. (1979b) cuja metodologia de cálculo se acha detalhada em Marques (1976, 1978).

A partir das expressões,

$$
\omega=\frac{\partial p}{\partial t}+\vec{v} \cdot \nabla p
$$

e

$$
\frac{d q}{d t}=\frac{\partial q}{\partial t}+\vec{v} . \nabla q, \ldots \ldots .
$$

mediante as condições físicas impostas ao problema chegou-se à seguinte expressão, aplicável para médias anuais e grandes regiões :

$$
\begin{aligned}
& \frac{\partial}{\partial t} \int_{1} \frac{1}{g} q d p+\nabla \quad \int \frac{1}{g}-\overrightarrow{q V d p}= \\
& -\frac{1}{g}(q \omega)+\frac{1}{g}\left(q_{c} \dot{\omega}\right)_{s} \ldots \ldots \text { (3) }
\end{aligned}
$$

onde os termos

$\overrightarrow{\mathrm{Q}}=\frac{1}{\mathrm{~g}} \int \overrightarrow{\mathrm{qVd}}$

- representa o campo do escoamento aéreo de vapor d'água (Marques et al., 1979a);

$W=\frac{1}{g} \int \overline{q d p}$

- representa o armazenamento aéreo do va por d'água (Marques et al., 1979b);

$E=-\frac{1}{g}(\dot{q} \omega)$

- é o fluxo vertical ascendente de vapor d'água que atravessa uma superfície s, representado pela evapotranspiração real;

$P=\frac{1}{g}\left(\dot{q}_{c} \omega\right)$

- é o fluxo vertical descendente de água na fase condensada c que atravessa uma superfície s, representada pela precipitação.

Assim, a expressão (3) pode ser escrita na seguinte forma:

$$
\frac{\partial \mathrm{W}}{\partial \mathrm{t}}+\nabla \cdot \overrightarrow{\mathrm{Q}}=\mathrm{E}-\mathrm{P} \ldots \ldots \ldots .
$$

Para a bacia Amazônica, verificou-se que a variação do armazenamento aéreo de vapor d'água foi desprezível. Marques et al. (1976, 1978) quando comparado com os demais termos da expressão (4), o que nos permite utilizá-la na seguinte forma simplificada:

$$
\nabla \cdot \overrightarrow{\mathrm{Q}}=\mathrm{E}-\mathrm{P} \ldots \ldots \ldots \ldots \ldots
$$

Quando $\nabla \cdot \vec{Q}>0$ em uma região, haverá aí urna fonte de umidade para a atmostera, isto é, para o mesmo período haverá, em média, um excesso da evaporação sobre a precipitação. Quando o valor é negativo (convergência) existirá um sumidouro de vapor dágua, em conseqüência de ser a precipitação maior que a evaporação. Nestes casos, as regiōes devem possuir um meio de dispor do excesso de água, implicando na existência de bacias de drenagem. Assim, áreas de convergência dos campos do fluxo coincidirão com áreas de 
grandes bacias. Por outro lado as regiões de forte divergência constituem fonte de umidade para a atmosfera e, geralmente, acharn-se so. bre oceanos e desertos.

\section{Uso do método aerológico para estimativa da vazão em uma bacia hidrográfica}

Para períodos relativamente longos, a equação clássica da Hidrologia se reduz a

$$
E-P=-r \ldots \ldots \ldots \ldots \ldots
$$

isto é, o escoamento superficial, representado pela vazão do rio. é mantido às expensas do balanço entre a evaporação e a precipitação no mesmo período.

\section{RESUltados OBTIDOS E DISCUSSÃO}

\section{A precipitação média, $\overline{\mathrm{P}}$}

A análise das cartas de precipitação, figuras 1 a 5 , evidenciou que o deslocameno meridional do Sol, atuando como fonte de energia para os processos convectivos, e o oceano Atlântico, fornecendo vapor d'água para a região, são os responsáveis pelos padrões de distribuição de chuva que ocorrem na Amazônia.

De janeiro a março, a faixa de máximos de chuva situa-se entre os paralelos $0-10^{\circ} \mathrm{S}$ tendo, a partir de março, um deslocamento progressivo em direção ao hemisfério norte. No periodo de junho a setembro, observam-se os menores valores da precipitação na parte sul da bacia.

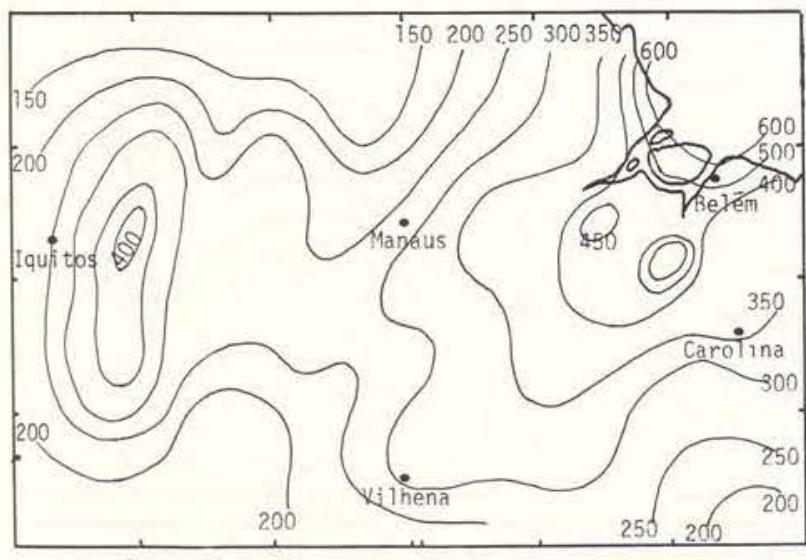

Fig. 1 - Distribuição da precipitação média do mês de março. Período 1972/1975. Isoietas graduadas em mm.

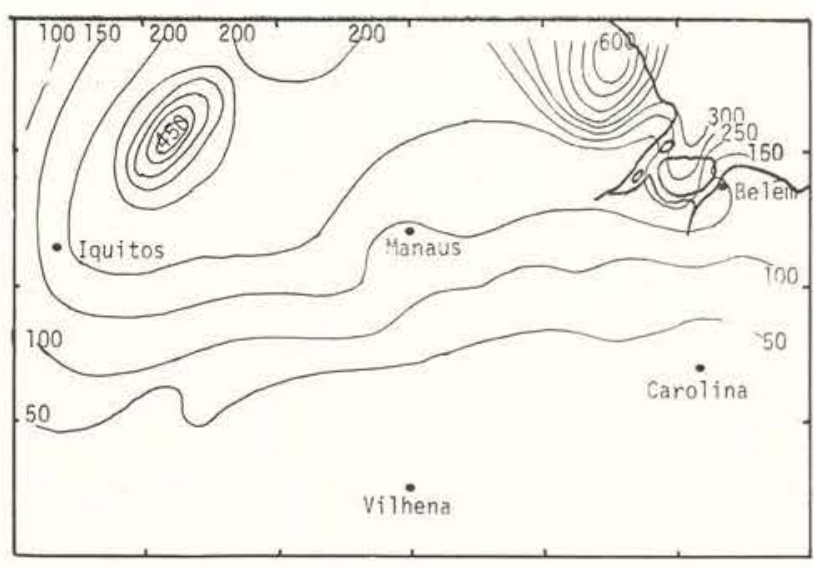

Fig. 2 - Distribuição da precipitação média do mês de junho. Período 1972/1975. Isoietas graduadas em mm.

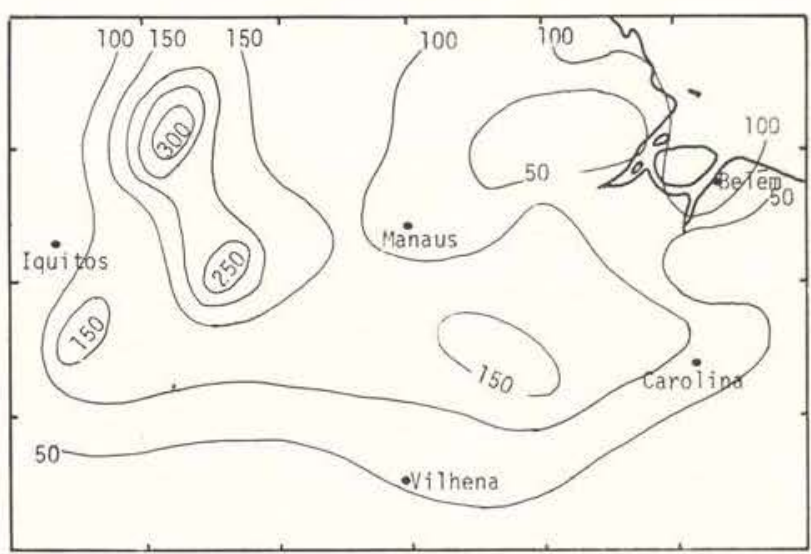

Fig. 3 - Distribuição da precipitação média do mês de setembro. Período 1972/1975. Isoietas graduadas em mm.

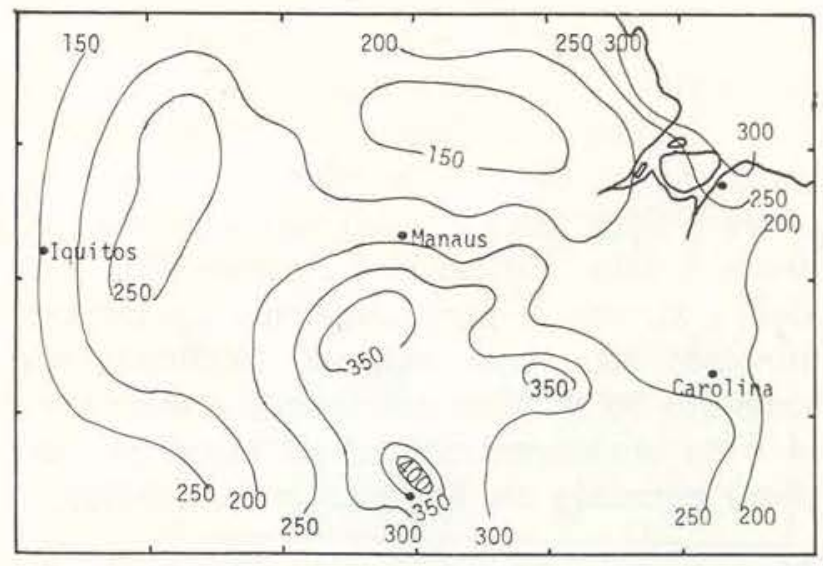

Fig. 4 - Distribuição da precipitação média do mês de dezembro. Período 1972/1975. Isoietas graduadas em mm. 


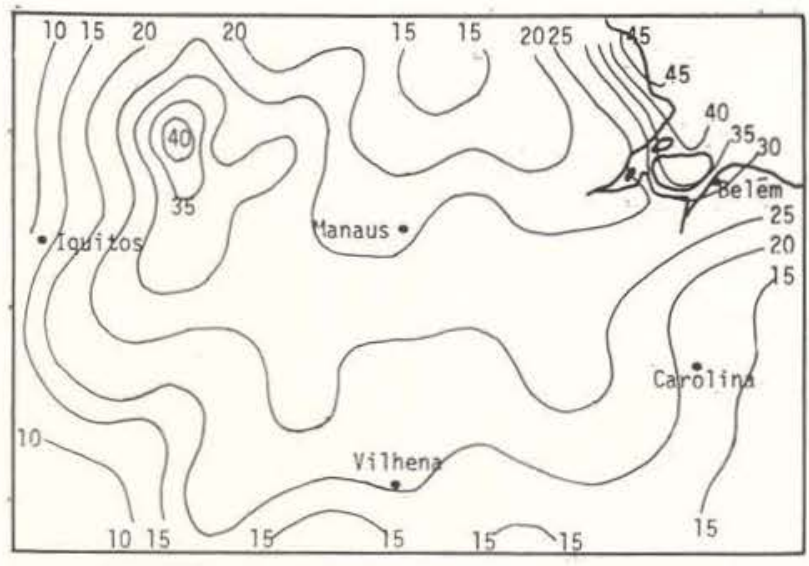

Fig. 5 - Distribuição da precipitação média anual do período 1972/1975. Isoietas graduadas em $10^{2} \mathrm{~mm}$.

Utilizando-se o método de isoietas, foram estimados os seguintes valores médios das precipitações :

\begin{tabular}{lcc}
\hline Mês & $\begin{array}{c}\text { Precipitação } \\
(\mathrm{mm})\end{array}$ & $\begin{array}{c}\text { média } \\
\left(10^{12} \mathrm{~m}^{5}\right)\end{array}$ \\
\hline Março & 286 & 1,46 \\
Junho & 164 & 0,84 \\
Setembro & 109 & 0,56 \\
Dezembro & 219 & 1,12 \\
\hline Mensal & 194 & 0,99 \\
Anual & 2328 & 11,88 \\
\hline
\end{tabular}

Para a média anual dó período estudado, figura $5 \mathrm{a}$, faixa de máximos acha-se distribuída ao longo da zona compreendida entre os paralelos de $5^{\circ} \mathrm{S}-5^{\circ} \mathrm{N}$, com outros distintos de máximos, locados em $52^{\circ} \mathrm{N}$ e $69^{\circ} \mathrm{N}$. Ao longo do Equador, a partir do litoral, os totais anuais das chuvas vão decrescendo, desde o valor $4500 \mathrm{~mm}$ até alcançar 2000 próximo a Manaus; a partir daí, começa a crescer atingindo seu novo máximo $(4000 \mathrm{~mm})$ em torno dos $69^{\circ} \mathrm{W}$. Esta distribuição é semeihante à do armazenamento aéreo (água precipitável) estudado em Marques et al. (1979b).

Divergência média do campo do fluxo de vapor $\vec{\nabla} \cdot \vec{Q}$
De um modo geral, na bacia Amazônica houve uma predominância do valor negativo da divergência. Comparando-se estes campos de $\overrightarrow{-\overrightarrow{\nabla Q}}$ com a de $\bar{P}$ no mesmo período, notase uma semelhança de configuração entre eles.

Analisando a figura 6 , observa-se que em março existiu um domínio quase total da ảrea convergente coincidindo com a época de máximos valores da precipitação observada na área conforme constatado por Azevedo (1974) e Salati et al. (1978). Na figura 11, para comparação, estão os histogramas das chuvas de várias localidades na bacia.

Em junho, figura 7, com a zona divergente dominando metacie da bacia, teremos menores valores para a precipitação nesta área.

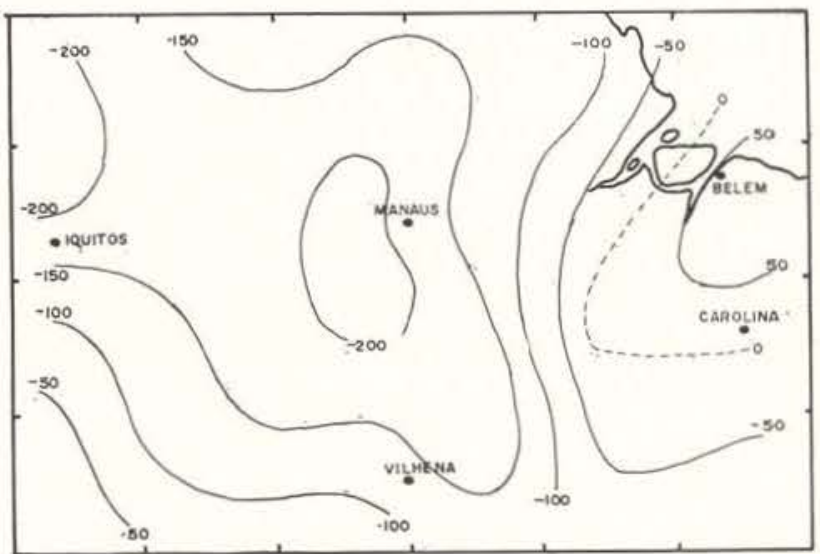

Fig. $6 \rightarrow$ Campo da divergância do fluxo de vapor médio, $\nabla . \vec{Q}$, para março. Média do período 1972/1975. Isolinhas graduadas $\mathrm{em} \mathrm{mm}$.

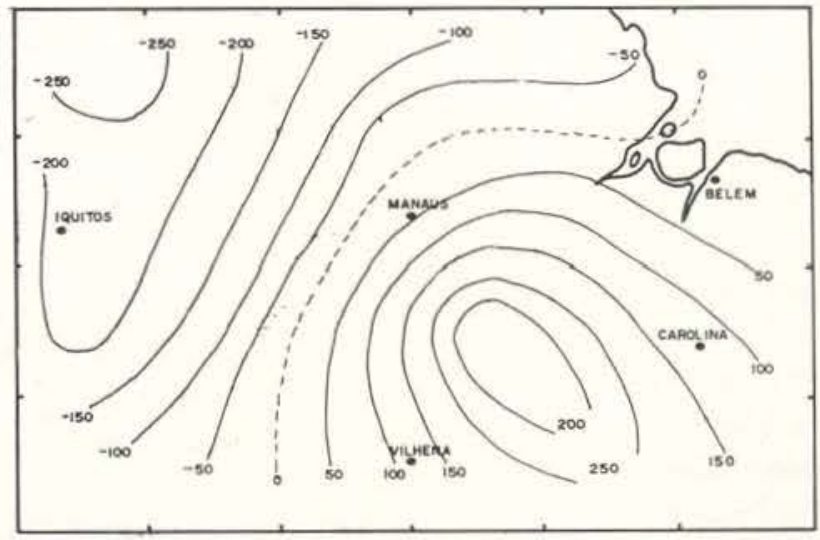

Fig. 7 - Campo da -divergência do fluxo de vapor, $\nabla \cdot \vec{Q}$, para o nıês de junho. Média do período 1972/1975. Isolinhas em $\mathrm{mm}$. 
ao passo que o deslocamento da área convergente para a região do alto Amazonas, Venezuela e Colômbia, produzem ali os máximos de chuva. A partir desta época a área diver. gente irá diminuir, possibilitando a evolução da zona convergente até alcançar seu máximo em março, indo assim o ciclo se repetir.

Não foi encontrada uma relação numérica entre os valores de $\mathrm{P}$ e $-\bar{\nabla} \cdot \overrightarrow{\mathrm{Q}}$, porém há uma grande justaposição entre as áreas convergentes e as de maiores valores da precipitação.

Da análise das figuras 6 a 10, em conjunto com o campo do transporte de vapor estudado em Marques et al. (1979a), as seguintes informações podem ser obtidas :

- no mês de março, praticamente em toda a bacia os valores de precipitação excedem aos da evapotranspiração dando, em conseqüência, valores negativos para a divergência; pelo menos neste mês, as evidências demonstram que a maior parte do vapor é de origem oceânica;

- para o mês de junho, a área divergente avançou por sobre grande parte da bacia e grande parte da evaporação local está sendo transportada para o interior isto é, a área abrangendo Belém-Manaus-Carolina-Vilhena também funciona com fonte de vapor para o resto da bacia; em setembro, a área divergente já

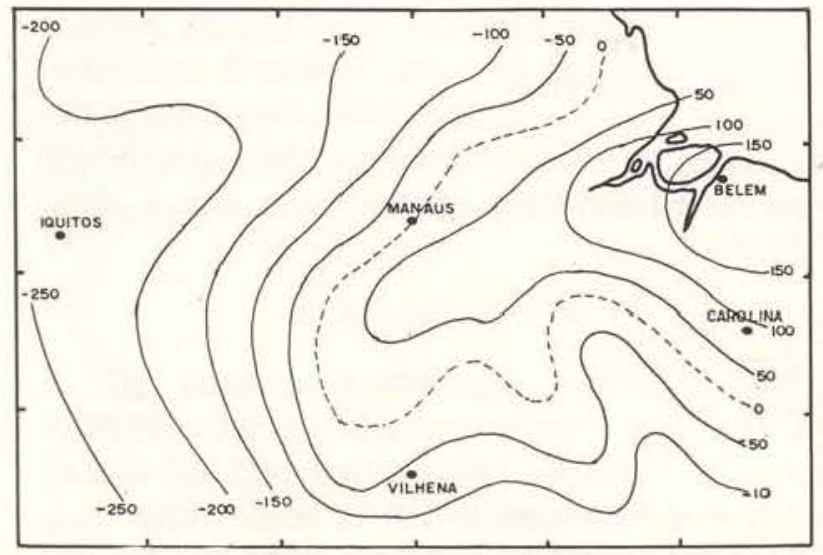

Fig. $8 \rightarrow$ Campo da divergência do fluxo de vapor médio, $\nabla . \vec{Q}$, parı setembro. Média do período $1972 / 1975$. Isolinhas graáuadas $\mathrm{em} \mathrm{mm}$.

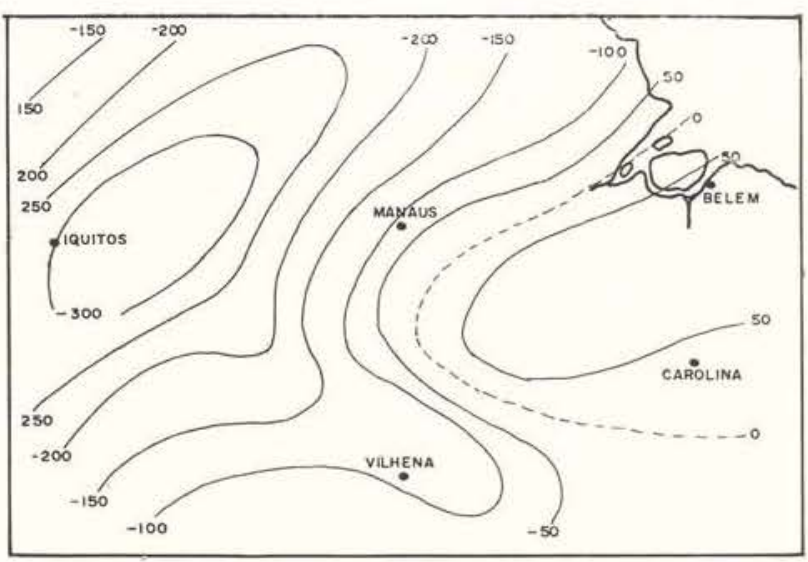

Fig. $9 \rightarrow$ Campo da divergência do fluxo de vapor médio, $\nabla . \vec{Q}$, para dezembro. Média do período 1972/1975. Isolinhas graduadas em $\mathrm{mm}$.

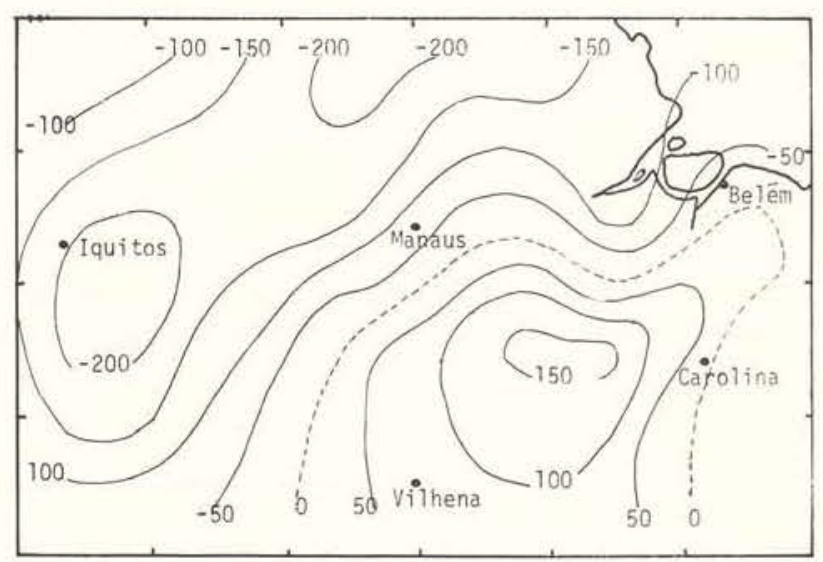

Fig. $10 \rightarrow$ Campo da divergência do fluxo médio mensal, $\vec{\nabla} \cdot \vec{Q}$. Média do periodo 1972/1975. Isolinhas graduadas em $\mathrm{mm}$.

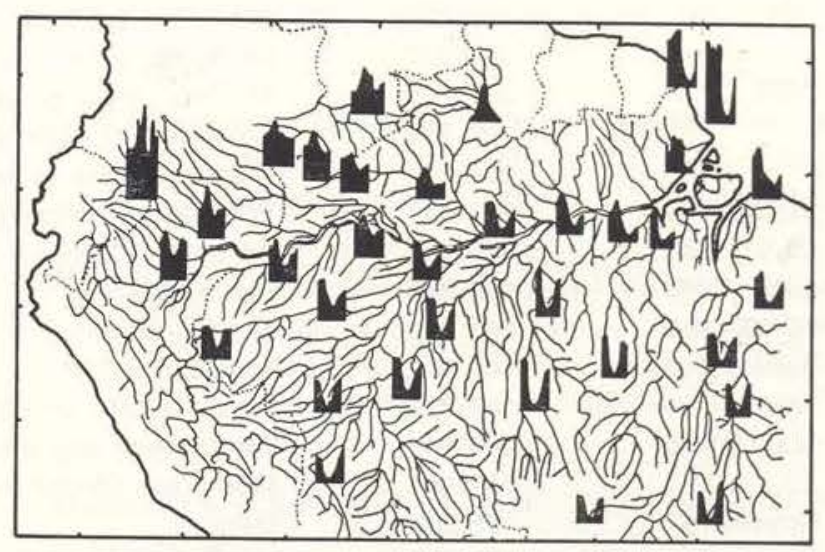

Fig. 11 - Distribuição das chuvas na bacia Amazônica (Salati et al., 1978). 
está bem menor; em dezembro, ela permanece praticamente inalterada, purém os valores da área convergente são bem maiores que no período anterior.

- ao longo da calha principal da bacia Amazônica e, mais precisamente, no trecho Manaus-lquitos, verificam-se os maiores valores da convergência da precipitação e da água precipitável. Como os valores do fluxo Marques et al. (1979a), nesta região decrescem de modo acentuado a partir de Manaus em direção à cordilheira, infere-se que um forte mecanismo de recirculação do vapor d'água tem lugar neste trecho.

\section{A divergência do fluxo e as vazões do rio Amazonas.}

Aplicando-se a metodologia descrita em uso do método aerológico estimaram-se as va- zões ( $r$ ) do rio Amazonas, cujos resultados se acham na tabela 1, comparados com os demais dados encontrados na literatura.

A convergência do fluxo de vapor $(\cdot \nabla \cdot \vec{Q})$ em determinado mês não deve necessariainente corresponder uma vazão $(r)$ no mesmo período. No presente estudo, a região de máximos valores para a convergência situa-se a quase $2500 \mathrm{Km}$ da foz do rio, sendo válido ad. mitir-se um período razoavelmente longo para que toda a água precipitada alcance a foz, principalmente levando-se em conta a pequena declividade da superfície da água do rio Amazonas, estimada por Soares (1956) citado por Oltman et al. (1964) como sendo da ordem de $65 \mathrm{~m}$ em $3000 \mathrm{Km}$.

A figura 12 mostra as vazões estimadas, aplicando o método aerológico para o periodo $1972 / 1975$ e as vazões obtidas segundo os dados de Oltman (1967) para o período 1963/ 1964 mas ajustando os dados às medições fei-

TABELA 1 - Resultados estimados para as vazōes do rio Amazonas, em $\mathrm{m}^{3} / \mathrm{s}$, na foz, utilizando o método aerológico, comparados com os obtidos por outros autores utilizando cutros métodos (Marques, 1978).

\begin{tabular}{|c|c|c|}
\hline Época & Vazão $\left(\mathrm{m}^{3} / \mathrm{s}\right)$ & observações \\
\hline $\begin{array}{l}\text { Setembro } \\
\text { Janeiro } \\
\text { Março } \\
\text { Média }\end{array}$ & $\begin{array}{l}115.104 \\
127.893 \\
224.686 \\
172.616\end{array}$ & $\begin{array}{l}\text { Média do período } 1972 / 1975 \text { utilizando o método aerológico para a previsão da } \\
\text { estimativa da varão na foz do rio Amazonas. } \\
\text { Idem } \\
\text { Idem } \\
\text { Idem } \\
\text { Idem }\end{array}$ \\
\hline \multirow[t]{2}{*}{$1928 / 1946$} & 186.892 & Média do período $1928 / 1946$, em Óbidcs (1) \\
\hline & 233.615 & Idem, na foz do rio Amazonas (1) \\
\hline \multirow[t]{2}{*}{1953} & 280.000 & Máxima descarga provável ocorrida (1) \\
\hline & $\begin{array}{r}90.000 \\
124.610\end{array}$ & $\begin{array}{l}\text { Média em Óbidos, citado por Pardé (1956) (1) } \\
\text { Média; Durum et alii (1960) (1) }\end{array}$ \\
\hline $16 / 07 / 1963$ & 212.800 & Próximo a óbidos (1) \\
\hline $20 / 07 / 1963$ & 149.038 & Próximo a Manaus (1) \\
\hline Junho/1963 & 216.342 & Em óbidos (1) \\
\hline 09/08/1964 & 160.000 & Em Óbidos (1) \\
\hline \multirow[t]{2}{*}{ Agosto/1964 } & 161.406 & Em Óbidos (1) \\
\hline & 177.430 & VILLA NOVA, et alii (1976) \\
\hline Maio/junho & 240.000 & Em Óbidos, segundo OLTMAN et al., citado por Villa Nova et alii (1976) \\
\hline \multirow[t]{3}{*}{ Novembro } & $\begin{array}{r}157.000 \\
85.000\end{array}$ & $\begin{array}{l}\text { Média em Óbidos, segundo OLTMAN citado por Villa Nova (1976) } \\
\text { Idem }\end{array}$ \\
\hline & 177.430 & VILLA NOVA et alii (1976) \\
\hline & 175.000 & Média na foz do rio Amazonas, segundo OLTMAN citado por Villa Nova et alii (1976) \\
\hline
\end{tabular}

(1) - FONTE: Brasil, Ministério das Minas e Energia (1964). 


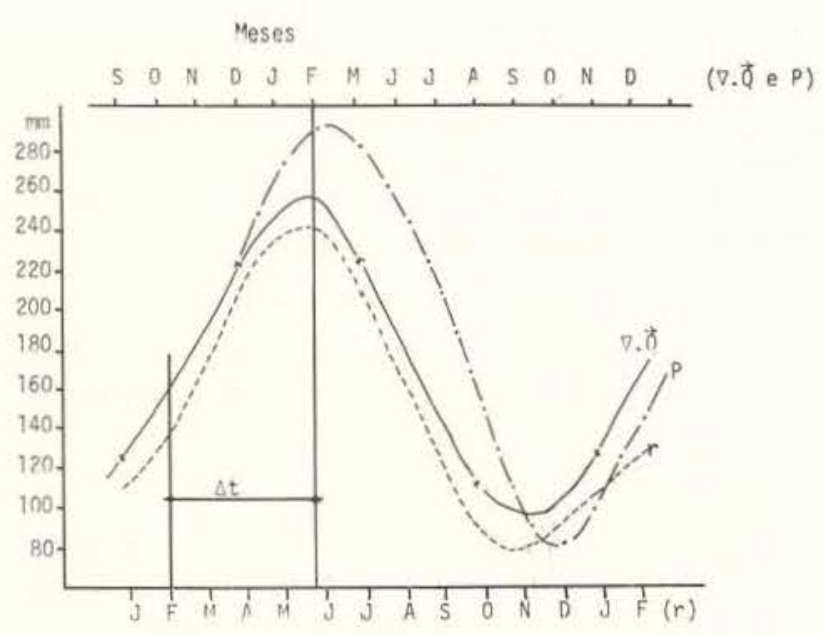

Fig. 12 - Valores mensais da descarga estimada $(\nabla . \vec{Q})$ aplicando o método aerológico; da precipitação P. mé. dia do período 1972/1975; da descarga ( $r$ ), segundo os dados de Oltman (1967). Valores em $\mathrm{mm}$.

tas com régua no período 1928/1946 em Óbidos segundo os valores constantes na tabela 2. Constata-se que as vazões estimadas por Oltman acham-se defasados aproximadaniente de 3,5 meses em relação aos valores estimados para a $\nabla . \vec{Q}$. Mesmo levando-se em conta que os valores de $r$ e $\nabla \cdot \vec{Q}$ não correspondem ao mesmo período, o método apresenta-se válido inclusive para prever, com razoável acerto as vazões do rio Amazonas, com mais de 3 meses de antecedência, independente do conhecimento dos valores da precipitação e evapotranspiração na região, tão necessários quando se utiliza a equação fundamental da Hidrologia Clássica, uma vez que os dados de radiossondagem são obtidos e transmitidos diariamente pela rede sinótica de aititude, estando assim prontamente disponiveis.

\section{AgRADECIMENTOS}

Os autores agradecem a FINEP, CNPq, FAPESP, CNEN e Secretaria de Tecnologia do Estado de São Paulo pelos recursos concedidos; à SUDENE, ao Ministério da Aeronáutica (Divisão de Meteorologia/DEC e DCA/CTA), à Força Aérea Venezuelana, à EMBRAPA/ CPATU e ao INPA pela cessão dos dados meteorológicos de superfície e/ou de altitude necessários a esta pesquisa.

\section{SUMMARY}

Water vapor divergences $\nabla \overrightarrow{.}$, are estimated over the Amazonas basin with radiossonde data from 1972/1975. Negative values for divergence were predominant over the basin and using the "aerological method" the mean Amazonas river discharge was estimated in $172,616 \mathrm{~m}^{3} / \mathrm{s}$; showed to be an independent method for estimatives of discharges from large basin independently of knowledge of precipitation and evapotranspiration values. The mean precipitation value estimated for $1972 / 1975$ period was $2,328 \mathrm{~mm} /$ year.

\section{BIBLIOGRAFIA}

AZEVEDO, D.C.

$$
\begin{aligned}
& 1974 \text { - Chuvas no Brasil - regime, variabilidade } \\
& \text { e probabilidades de alturas mensais e } \\
& \text { anuais. Tese de Mestrado - Univ. Fed. } \\
& \text { Rio Grande do Sul. }
\end{aligned}
$$

Benton, G.S.; Blackburn, R.T. \& Sneao, V.O.

1950 - The role of the atmosphere in the hydro. logic cycle. Trans. Am. Geophys. Un., $31: 61-73$.

Benton, G.S. \& Estoque, M.A.

1954 - Water-vapor transfer ever the North American Continent. J. Met., 11: 462-477.

BetTENCOURT, M.L. \& FARIA, J.M.R.

1970 - The water vapor in the atmosphere and the hydrological cycle. Idöjárás, Budapest. (5-6) : 307-312.

HUTCHINGS, J.W.

1957 - Water-vapor flux and flux-divergence over Southern England: summer 1954. Quart. J. Royal Met. Soc., London, 83 : 30-48.

1961 - Water-vapor transfer over the Australian continent. J. Met., $18: 615-634$.

Marques, J.

1976 - Contribuição ao estudo hidrológico da bacia Amazônica. Dissertação MS. Escola Superior de Agricultura "Luiz de Queiroz"/USP, $116 \mathrm{p}$.

1978 - A transferência horizontal de vapor dágua na troposfera e a hidrologia da bacia Amazônica. Tese de Doutoramento. Escola Superior de Agricultura "Luiz de Queiroz"/ USP, $112 \mathrm{p}$.

Marques, J.; Santos, J.M. dos; Villa Nova, N.A. \& SALATT, E.

1977 - Precipitable water and water vapor flux between Belém and Manaus. Acta Amazonica, Manaus, $7(3): 355-362$. 
Marques, J.; Santos, J.M. dos \& Salati, E.

1979a - O campo do fluxo de vapor d'água atmos. térico sobre a regiāo amazônica. Acta Ama. zonica, Manaus, 9(4) : 701-713.

Marques, J.; Salati, E. \& Santos, J.M. dos

$1979 \mathrm{~b}$ - O armazenamento atmosférico de vapor stágua sobre a região Amazônica. Acta Amazonica, Manaus, 9(4): 715-721.

Molion, L.C.B.

1975 - A climatonomic study of the energy and moisture fluxes of the Amazonas ba:in with considerations of deforestation effects. PhD. Thesis, University Wisconsin, Madison, $133 \mathrm{p}$.

Oltman, R.E.; Sternberg, H.O.R.; Ames, F.C. \& OAVIS, J.R.

1964 - Investigaçōes no rio Amazonas. Reconhecimento das mediçôes de julho de 1963. Circ. 486, Geological Survey, Wash. - Traduçăo de Stelio Souza, In: Brasil, MME, 1964. As mais recentes medições do rio Amazonas. Div. Tec. n. ${ }^{1}$, DNPM, DA, em colab. com Univ. do Pará, $81 \mathrm{p}$.

OLtMAN, R.E.

1967 - Peconnaissame investigations of the discharge and water quality of the Amazon. In: Atas do Simpósio sobre a Biota Amazô. nica, Rio de Janeiro, 3 (Limnologia): 163-185.

Palmén, E. \& Söderman, D.

1966 - Computation of the evaporation from Baltic Sea from the flux of water vapor in the atmosphere. Geophysica, $8: 261-279$.
PEIXoto, J.P.

1968 - O ramo aéreo do ciclo hidrológico. Fomento, Lisboa, 6(2): 111-119.

1970 - Water vapor balance on the atmosphere from five years of hemispheric data. Nordic Hydrology, Copenhagen, 2:120-138.

Peixoto, J.P.: Rosen, R.D. \& Wu, MAO-Fu

1976 - Seasonal variability in the Pole-to-Pole water vapor balance during the IGY. Nordic Hydrology, Denamark, $7(2): 95-114$.

RASMUSSON, E.M

1966 - Diurnal variations in the summer water vapor transport over North America. Water Resources Research, 2(3) : 469-477.

1967 - Atmospheric water-vapor transport and the water balance of North America. Month Weather Rev., 95: 403-425.

Salati, E.; Marques, J. \& Molion, L.C.B.

1978 - Origem e distribuiçăo das chuvas na Ama. zônia, Interciência. 3(4) : 200-205.

SOARES, L. DE C.

1956 - Amazônia, 18. Congresso Internacional de Geografia, Rio de Janeiro, UGI - Comissão Nacional do Brasil. Guia de Excursão, 8. 320 p.

(Aceito para publicaçăo em 28/09/79) 